\title{
Depression prevalence in disadvantaged young black women
} African and Caribbean immigrants compared to US-born African Americans

Accepted: 25 August 2004

Abstract Background Research with Mexican Americans suggests that immigrants have lower rates of mental disorders than U. S.-born Mexican Americans. We examine the prevalence of depression, somatization, alcohol use and drug use among black American women, comparing rates of disorders among U.S.-born, Caribbean-born, and African-born subsamples. Methods Women in Women, Infants and Children (WIC) programs, county-run Title $\mathrm{X}$ family planning clinics, and low-income pediatric clinics were interviewed using the PRIME-MD. In total, 9,151 black women were interviewed; 7,965 were born in the U.S., 913 were born in Africa, and 273 were born in the Caribbean. Results Controlling for other predictors, U.S.-born black women had odds of probable depression that were 2.94 times greater than the African-born women ( $<<0.0001,95 \%$ CI: 2.07 , 4.18) and 2.49 times greater than Caribbean-born women ( $\mathrm{p}<0.0016,95 \%$ CI: 1.41, 4.39). Likelihood of somatization did not differ among women who were U.S. born, African born, or Caribbean born. Rates of alcohol and drug problems were exceedingly low among all three groups, with less than $1 \%$ of the women reporting either alcohol or drug problems. Conclusions These results mirror similar findings for Mexican immi-

J. Miranda, Ph.D. (赤) · J. Siddique, M.S. · T. R. Belin, Ph.D.

UCLA Neuropsychiatric Institute

UCLA Wilshire Center

10920 Wilshire Blvd., Suite 300

Box 957082

Los Angeles (CA) 90095-1736, USA

Tel.: + 1-310/794-3719

Fax: + 1-310/794-3724

E-Mail:mirandaj@ucla.edu

T. R. Belin, Ph.D.

Dept. of Biostatistics

University of California at Los Angeles School of Public Health

Los Angeles (CA), USA

L. P. Kohn-Wood, Ph.D.

Dept. of Psychology

University of Michigan

Ann Arbor, (MI), USA grant as compared with American-born Mexican Americans. The findings suggest that living in the U.S. might increase depression among poor black women receiving services in county entitlement clinics. Further research with ethnically validated instruments is needed to identify protective and risk factors associated with depression in immigrant and U.S.-born poor black women.

Key words depression - African American immigrant - mental health

\section{Introduction}

The black population in the United States is becoming more heterogenous through migration. Between 1970 and 2000, the share of foreign-born blacks in the overall black population rose nationwide to $7.8 \%$ from $1.3 \%$ [1]. Black immigrants come primarily from Africa and the Caribbean. These population changes suggest that black Americans are becoming a diverse group and, like Latinos, represent different cultures and nationalities. This study examines differences in mental health between U.S.-born, Caribbean-born, and African-born black women who seek county entitlements.

The mental health of immigrants has been the subject of debate in psychiatry since the end of the nineteenth century [2]. Early studies reported poor mental health among immigrant populations and argued that acculturation (or assimilation into mainstream culture) was needed to improve the mental health status of immigrants $[3,4]$. Unfortunately, empirical research on acculturation and mental health status has yielded conflicting results [5].

Recently, well-designed studies of Latino populations have examined mental health differences by immigration status. These studies show consistent differences in rates of mental disorders between immigrant and U.S.born populations. Over a decade ago, the Los Angeles Epidemiologic Catchment Area study reported that U.S.-born Mexican Americans had higher rates of men- 
tal disorders than did Mexican immigrants [6]. For example, the prevalence of alcohol and other drug problems in the US-born subjects was more than three times that found in the subjects born in Mexico. Recently, the Mexican American Prevalence and Services Survey (MAPSS) [7] examined psychiatric disorders in urban and rural Mexican Americans in California. Mexican immigrants had lower lifetime rates, while rates for U. S.born Mexican Americans were higher, similar to those of the national population of the U.S.

The "healthy immigrant effect," where immigrants have fewer disorders than do U. S.-born populations, has been explained by theories of migration of the fittest [8]. Specifically, those who are healthiest are possibly also those who migrate. Interestingly, Vega and colleagues compared the data in their MAPSS study to a field survey conducted in Mexico City by researchers from the Mexican Institute of Psychiatry [9]. In these comparisons, the rates of mental disorders observed in the Mexico-born immigrants in the U.S. closely resembled those found in residents of Mexico City. They also found that the subsample of subjects who had lived fewer than 13 years in the U.S. had rates of psychiatric disorders comparable to rates observed in Mexico City; the subsample who had lived 13 years or more in the U.S. had higher rates, comparable to those in the U. S. population. These findings argue against a healthy immigrant effect and suggest that time living in the U.S. may account for the differences. In this study, we determine whether time in the U.S. relates to increased likelihood of disorder for immigrant black women.

To explain the superior mental health of Mexican immigrants, the strong cultural values of traditional Mexicans have been hypothesized as protective factors for immigrant populations [10]. An alternative explanation is that symptom expression is different among immigrants; in particular, Latino immigrants have been found to report more somatic symptoms than do White Americans [11]. In this study, we examine whether U. S.born and immigrant black women differ in likelihood of reporting multiple somatic symptoms.

To date, very little information on psychiatric problems among immigrant black Americans is available. Two studies in England have found higher depressive symptoms in Caribbean immigrants as compared with the general population [12] and higher rates of diagnoses of depression in Caribbean immigrants as compared with general practice patients [13]. We could find no published reports of African immigrant populations. Studies have examined rates of disorders among U.S.born African Americans. In the first large epidemiologic study of depression in the U. S. [14], 1-year prevalence of affective disorders was similar among African American $(5 \%)$ and white $(5.1 \%)$ women. Also, 1-year prevalence of alcohol abuse or dependence was similar in African American $(2.50 \%)$ and white women $(2.11 \%)$. One-year prevalence of drug abuse or dependence was higher in African American (2.33\%) as compared with white women $(1.31 \%)$. In that study, African American fe- males were more likely to report four or more somatic symptoms than were non-African American women (6.08\% vs. $3.88 \%)$.

In the National Comorbidity Study [15], the first nationally representative epidemiologic study of psychiatric disorder in the U.S., 1-year prevalence of depression was also similar among African Americans (8.2\%) and whites $(9.9 \%)$. In the most recent epidemiologic study, the National Comorbidity Survey Replication [16], the rate of 1 -year major depression was $6.6 \%$ overall, with no significant differences between African Americans and whites.

Because mental disorders in general, and substance abuse in particular, have been found to differ in Mexican immigrant and U.S.-born populations, we examine both in immigrant and U.S.-born black women. Because immigrant Mexican populations have been found to report higher somatic symptoms, possibly showing an alternative idiom of distress to depression, we compare immigrant and U.S.-born black women on rates of somatic symptoms. We compare rates of disorders among U.S.born, Caribbean-born, and African-born subsamples.

\section{Subjects and methods}

These data were obtained while screening prospective participants for the WE Care (Women Entering Care) study. WE Care was a randomized trial of treatment of depression in women who received county health and welfare services in the suburban Washington DC area (Prince Georges and Montgomery, Maryland, and Arlington and Alexandria, Virginia) [17]. The study was reviewed and approved by three institutional review boards with oversight responsibility. All participants were given written informed consent for screening.

\section{Sample}

We administered the WE Care screening interview to 16,286 women overall (11,151 Prince Georges County, 3,034 Montgomery County, 2,101 Arlington and Alexandria, Virginia). Screenings were conducted from March 1997 through May 2001; we began in Prince Georges County clinics and moved to Montgomery and Arlington Alexandria clinics. During screening, staff in the clinics asked all women attending the clinic if they would participate in the screening. A total of $1,576(8.8 \%)$ of the women approached declined to participate.

Women were screened in Women, Infants and Children (WIC) programs that target low-income pregnant and postpartum women and their children (up to 5 years of age). WIC mothers are likely to be poorer and younger than mothers who do not receive WIC [18]. African Americans are over-represented among WIC mothers [18]. Women were also screened in county-run Title X family planning clinics, funded by national grants for comprehensive family planning services for young ( $80 \%$ are below 30 [19]) and low-income women ( $57 \%$ are below poverty [19]). African American women are over-represented in family planning clinics.

We screened 10,043 women attending WIC services, 5,017 attending family planning clinics, 1,144 bringing children to pediatric services for low-income families, and 82 living in subsidized housing projects or attending programs for county welfare recipients. Of the total screened, 9,151 were black women based on self-identification. Of the black women who were screened, 7,965 were born in the U.S., 913 were born in Africa, and 273 were born in the Caribbean. 
All measures were obtained from personal interviews administered by WE Care project staff. Demographic information obtained in the interviews includes age, marital status, employment status, and level of education. Ethnicity and country of origin were obtained through two self-report items. Women were asked: "What is your cultural or ethnic identity?" and "Where were you born?"

To assess mental health problems, the Primary Care Evaluation of Mental Disorders (Prime-MD) [20] was used to identify women with significant somatic complaints and those at high risk for major depressive disorder during the past month. The Prime-MD uses modified Diagnostic and Statistical Manual of Mental Disorders (fourth revision) criteria [21] and reports good agreement with independent psychiatric diagnoses guided by a structured interview, with $92 \%$ overall accuracy for major depression [20]. Reports of agreement with primary care physicians' diagnosis of somatoform disorder had an overall accuracy of $46 \%$. Of the patients in this study establishing the psychometric properties of the PRIME-MD, $42 \%$ were minorities. In a follow-up study of young women seen in obstetrics-gynecology [22], similar diagnostic accuracy was attained. In this second study examining the psychometric properties of the PRIME-MD, $15 \%$ of the women were African American. Although separate estimates are not available for African American women, the instrument appears to be accurate in diverse populations.

Alcohol problems were ascertained using the 5-item (TWEAK) [23] designed for obstetric-gynecologic clinic patients. The instrument was found to have a sensitivity of 80 and specificity of 94 in identifying alcohol dependence in African American women [24]. In this current study, women who screened positive on the TWEAK for likely alcohol dependence or abuse were considered to have an alcohol problem. Other substance abuse problems were identified using stem items from the Structured Clinical Interview for Diagnostic and Statistical Manual of Mental Disorders, Fourth Edition (SCID) [25] No data are available on the diagnostic accuracy of these stem items. Women who answered positive during the past year for use of substances on the stem items were scored as having another substance abuse problem in this study.

\section{Data analyses}

Simple descriptive statistics were used to characterize the samples, and chi-square test and one-way analysis of variance were used to identify significant differences across subgroups defined by region of birth (U.S., African, Caribbean). Logistic regression analyses were conducted to examine the relation of depression diagnoses with demographic characteristics. An additional logistic regression analysis was run on the subset of immigrant women to determine the relationship of years in the U.S. with likelihood of having probable depression.

There are small rates of missing data $(0.03 \%-0.1 \%)$ for all demographic characteristics except years in the U.S. for which $5.8 \%$ of values were missing. First, data were analyzed using all cases with complete data. To avoid discarding any information, multiple imputation of missing data was performed. An approximate Bayesian bootstrap predicted mean matching hot-deck procedure was done separately for each group (U.S. born, African born, Caribbean born). Each demographic variable was predicted using the other demographic variables as predictors. Variables with the lowest number of missing values were imputed first. After imputing all demographic variables, these variables were used to impute the outcome variables. Because complete-case and multiple-imputation results were nearly identical, only regression analyses with multiply imputed data are presented.

\section{Results}

\section{Participants}

The immigrant women in this study differed from the U.S.-born women in terms of demographic characteristics (Table 1). Most women in the study were young, with $95 \%$ of the sample younger than 43 . Compared to U.S.born black women, the immigrant women were slightly older, had more children, were better educated on average; the immigrant women were also more likely to be married, to be uninsured, to live in their own house or apartment, but less likely to be employed full time.

We also examined differences in likelihood of having major depression. Immigrant women were less likely to have probable depression than were U.S.-born women (10.5\% U.S. born, 3.9\% African born, $4.8 \%$ Caribbean born, $\mathrm{p}<0.0001)$. The rates for the U. S.-born women are similar to rates found in a large screening study in primary care, where $10 \%$ were depressed [20], but higher than those found among obstetrics and gynecology outpatients where $6 \%$ were depressed [22].

Rates of somatization were similar across the three groups of black women. Rates of alcohol and drug problems were exceedingly low among all three groups, with less than $1 \%$ of the women reporting either alcohol or drug problems. Finally, a very small number of women had entered mental health treatment. Only $2.6 \%$ of U. S.born, $0.8 \%$ of African-born, and $2.6 \%$ of Caribbeanborn women were in current mental health treatment. For the U.S.-born women, $9 \%$ of those who screened positive were in treatment and $1.8 \%$ of those who screened negative were in treatment. For the Africanborn women, $2.8 \%$ of those who screened positive and $0.6 \%$ of those who screened negative were in treatment, and, of the Carribean-born women, none of those who screened positive and $2.3 \%$ of those who screened negative were in treatment.

To determine whether place of birth is associated with depression, logistic regression analyses were computed, controlling for age, number of children, marital status, education, increasing insurance status and housing, all of which showed differences across region of birth (Table 2). Results show that immigration status did relate to likelihood of major depression even after controlling for demographic differences among the samples. Specifically, controlling for other demographic factors, U.S-born black women had odds of probable depression that were 2.94 times greater than those of the African-born women ( $\mathrm{p}<0.0001,95 \%$ CI: 2.07, 4.18) and 2.49 times greater than those of Caribbean-born women ( $p<0.0016,95 \%$ CI: 1.41, 4.39). Similar analyses were conducted to determine the likelihood of somatization by immigration status. Likelihood of somatization did not differ among women who were U.S. born, African born, or Caribbean born.

To determine the relationship of years in the U.S. with likelihood of major depression for immigrant 
Table 1 Demographic and clinical characteristics by country of birth*

\begin{tabular}{|c|c|c|c|c|}
\hline Demographic characteristics & U.S. born & African born & Caribbean born & $F$ ( $p$ value) \\
\hline $\mathrm{N}$ & $7,965 \bar{x}(S D)$ & $913 \bar{x}(S D)$ & $273 \bar{x}(S D)$ & \\
\hline Age & $28.7(8.5)$ & $32.4(6.6)$ & $31.1(7.4)$ & $118.5(p<0.0001)$ \\
\hline Years in U.S. & - & $7.9(6.8)$ & $1,205(7.7)$ & $84.1(p<0.0001)$ \\
\hline Number of children & $1.9(1.5)$ & $2.2(1.3)$ & $2.2(1.5)$ & $15.5(p<0.001)$ \\
\hline \multirow[t]{2}{*}{ Marital status } & & & & $400.1(p<0.0001)$ \\
\hline & $N(\%)$ & $N(\%)$ & $N(\%)$ & $\chi^{2}$ (p value) \\
\hline Married/living with partner & $2,509(31.5)$ & $574(62.9)$ & $127(46.5)$ & \\
\hline Widowed/separated/divorced & $964(12.1)$ & $106(11.6)$ & $41(15.0)$ & \\
\hline Never married & $4,484(56.3)$ & $233(25.5)$ & $105(38.5)$ & \\
\hline Education status & & & & $461.5(p<0.0001)$ \\
\hline Below HS graduate & $749(9.4)$ & $57(6.3)$ & 40 (14.7) & \\
\hline HS graduate & $3,427(43.1)$ & $312(34.3)$ & $93(34.1)$ & \\
\hline Some college/technical & $3,150(39.6)$ & $264(28.9)$ & $106(38.8)$ & \\
\hline College graduate & $633(8.0)$ & $277(30.4)$ & $34(12.5)$ & \\
\hline Insurance & & & & $215.0(p<0.0001)$ \\
\hline Uninsured & $2,319(29.2)$ & $467(51.2)$ & $124(45.4)$ & \\
\hline Medical assistance & $2,327(29.3)$ & $191(20.9)$ & $50(18.3)$ & \\
\hline Private & $3,306(41.6)$ & $248(27.2)$ & $99(36.3)$ & \\
\hline Employed full time & $3,395(42.6)$ & $264(28.9)$ & $102(37.4)$ & $65.2(p<0.0001)$ \\
\hline Homemaker full time & $431(5.4)$ & $57(6.2)$ & $22(8.1)$ & ns \\
\hline Housing & & & & $228.7 P<0.0001)$ \\
\hline Own house/apartment & $5,363(67.3)$ & $727(79.6)$ & $214(78.4)$ & \\
\hline Parents & $1,653(20.8)$ & $16(1.8)$ & $22(8.1)$ & \\
\hline Family/friends & $907(11.4)$ & $167(18.3)$ & $36(13.2)$ & \\
\hline Shelter/homeless & $26(0.3)$ & $2(0.2)$ & $0(0)$ & \\
\hline \multicolumn{5}{|l|}{ Clinical characteristics } \\
\hline Major depression & $833(10.5)$ & $36(3.9)$ & $13(4.8)$ & $41.8(p<0.0001)$ \\
\hline Somatization & $34(2.8)$ & $29(3.2)$ & $9(3.3)$ & ns \\
\hline Alcohol problems & $11(0.1)$ & $1(0.1)$ & $0(0)$ & - \\
\hline Drug problems & $35(0.4)$ & 0 & $1(0)$ & - \\
\hline In treatment & $204(2.6)$ & $7(0.8)$ & 7 (3) & - \\
\hline
\end{tabular}

* Analysis conducted on imputed data

\begin{tabular}{llllr}
\hline Parameter & Odds ratio & $95 \%$ Cl lower & $95 \%$ Cl upper & p value \\
\hline Age & 1.00 & 0.99 & 1.01 & 0.8810 \\
Marital status & & & & \\
$\quad$ Married/living with partner (ref) & & & & \\
$\quad$ Widow/separated/divorced & 1.41 & 1.13 & 1.77 & 0.0027 \\
$\quad$ Never married & 0.84 & 0.71 & 1.00 & 0.0552 \\
Education & 0.76 & 0.69 & 0.84 & $<0.0001$ \\
Housing & & & & \\
$\quad$ Own house/apartment (ref) & 0.97 & 0.78 & 1.20 & 0.7626 \\
$\quad$ Parents & 1.40 & 1.13 & 1.72 & 0.0018 \\
$\quad$ Family/friends/shelter & & & & \\
Insurance status & & & & \\
$\quad$ Private (ref) & 1.65 & 1.38 & 1.97 & 0.0001 \\
$\quad$ Uninsured & 1.43 & 1.19 & 1.72 & 0.0002 \\
$\quad$ Medical assistance & 1.06 & 1.01 & 1.12 & 0.0264 \\
Number of children & & & & \\
Birthplace & & & & 0.0001 \\
$\quad$ USA (ref) & 0.34 & 0.24 & 0.49 & 0.0023 \\
$\quad$ Africa & 0.42 & 0.24 & 0.73 & \\
$\quad$ Caribbean & & &
\end{tabular}

${ }^{*}$ Analysis conducted on imputed data
Table 2 Odds of depression by birthplace controlling for demographic characteristics* 
women, we conducted a logistic regression controlling for age, number of children, marital status, education, increasing insurance status and housing (Table 3 ). We found a significant result $(\mathrm{p}=0.04)$ for years in the U.S. Based on the estimates from this model, an additional 10 years in the U.S. was associated with 1.35 times the odds of reporting probable depression.

\section{Discussion}

This study resulted in two key findings. Among black women attending county entitlement programs, those born outside the U.S., in either Africa or the Caribbean, are less likely to screen positive for probable depression than are women born in the U.S. Furthermore, rates of probable depression are related to length of time in the U.S. for immigrants.

One explanation for lower rates of depression among immigrant groups as compared with U.S.-born samples is that diagnostic categories are driven largely by Western psychiatry. Somatic symptoms may serve as a similar idiom of distress in different cultural groups. In this study, high levels of somatic symptoms were not more prevalent among immigrants than U.S.-born black women. This would suggest that the immigrant women are not experiencing multiple somatic symptoms in place of depressive symptoms. An alternative explanation is that those born in the U.S. are in some ways more deprived than their immigrant counterparts, resulting in increased rates of depression.

An important finding in this study is the low rate of substance abuse problems, less than $1 \%$, among these immigrant and U.S.-born black women. However, earlier general population studies have found higher rates of drug abuse and dependence in African Americans as opposed to white women [14]. Among women seeking family food subsidies and family planning, all substance use is minimal. Future research should address whether rates for immigrants increase over time in the U.S. or in subsequent generations.

The results of this study contrast with studies in England where immigrant populations from the Caribbean are found to have higher rates of depression than do those in the British general population. One possible explanation for the divergence of this study and ours could be that time since immigration may differ in the two studies. Our results suggest that rates of depression increase with time in the U.S. for the immigrant population in our study. If this phenomenon is true in England as well as the U.S. and Caribbean immigrants had been in England for extended periods of time, they could have higher rates of depression. On the other hand, the immigrants in our study were primarily young women, all of whom were seeking county health entitlements. Our results might have been different had they been in a general population of immigrants from the Caribbean in the U.S.

Differences in rates of depression among immigrant and U.S.-born black women may be related to differential exposure to risk and protective factors. One possibility is that growing up in the U.S. may expose black women to more chronic stressors. Although we did not measure such factors in our study, understanding the different risks and protective factors among U.S.-born and immigrant black women should be the topic of future research.

This study has a number of strengths and weaknesses that should be noted. In cross-cultural studies of mental health issues, methodological issues are particularly im-
Table 3 Odds of depression for immigrant women by years in the U. S.*

\begin{tabular}{lllll}
\hline Parameter & Odds ratio & $95 \%$ Cl lower & $95 \%$ Cl upper & p value \\
\hline $\begin{array}{l}\text { Birthplace } \\
\quad \text { Caribbean (ref) }\end{array}$ & & & & \\
$\quad$ Africa & 0.92 & 0.46 & 1.81 & 0.8018 \\
Age & 0.98 & 0.93 & 1.03 & 0.3902 \\
Marital status & & & & \\
$\quad$ Married/living with partner (ref) & & & & \\
$\quad$ Widow/separated/divorced & 1.00 & 0.39 & 2.54 & 0.9993 \\
$\quad$ Never married & 1.12 & 0.55 & 2.26 & 0.7546 \\
Education & 1.08 & 0.78 & 1.49 & 0.6438 \\
Housing & & & & \\
$\quad$ Own house/apartment (ref) & & & & \\
$\quad$ Parents & 0.96 & 0.21 & 4.43 & 0.9600 \\
$\quad$ Family/friends/shelter & 1.23 & 0.58 & 2.60 & 0.5849 \\
Insurance status & & & & \\
$\quad$ Private (ref) & & & & \\
$\quad$ Uninsured & 1.47 & 0.71 & 3.03 & 0.2964 \\
$\quad$ Medical assistance & 1.11 & 0.45 & 2.72 & 0.8186 \\
Number of children & 1.06 & 0.83 & 1.36 & 0.6435 \\
Years in U.S. & 1.04 & 1.00 & 1.07 & 0.0422 \\
\hline
\end{tabular}

* Analysis conducted on imputed data 
portant. Culture may shape the perception and expression of distress. Cultural factors could also lead to disproportionate denial of psychiatric symptoms. The extent to which the differences reported are real, as opposed to reflecting only cultural differences in symptoms, is unknown. The data in this study are based on self-report, with no external validation by a mental health professional. These self-report measures have generally been found valid for U.S. populations. The validity of these measures for Caribbean- and Africanborn populations has not been established. Despite these shortcomings, this study utilizes well-established measures and was able to document differences in understudied populations of immigrant black women.

The findings of this study are in line with those found in Mexican American populations where rates of psychiatric disorders appear lower for immigrants than for those born in the United States. Furthermore, time in the United States relates to increased likelihood of developing mental disorders. These findings have importance for public health. First, preventing the decline of mental health among immigrant women should be an important priority. In addition, these findings suggest important questions for further research that could improve public health. Understanding the factors that contribute to the positive mental health of immigrants could provide clues to preventing depression. Similarly, understanding how increased time in the U.S. may be related to increases in depression could also provide important information about factors that could decrease the incidence of depression. Finally, the discordance between rates of probable depression and rates of treatment among black women in this sample replicates previous evidence for high levels of unmet need in ethnic minority populations.

- Acknowledgements This work was supported by the John D. and Catherine T. MacArthur Foundation and NIMH RO1 MHS 6864. Four center grants supported Dr. Miranda's writing of this article (5P30MHO68639 (NIMH), 5P20MD000148 (NCMHD), 5P30A6021684 (NIA) and ISP01MH059876 (NIMH)).

\section{References}

1. April 2002: Population Today, Foreign-Born Make up Growing Segment of US, Black Population

2. Vander Stoep A, Link B (1998) Social class, ethnicity, and mental illness: The importance of being more than earnest. Am J Public Health 88(9):1396-1403

3. Malzberg B (1964) Mental disease among native and foreign born whites in New York State. Ment Hyg 48:478-499

4. Srole L, Langner TS, Michael ST, Kirkpatrick P, Opler MK, Rennie TAC (1962) Mental health in the metropolis: the Midtown Manhattan Study. New York: McGraw-Hill

5. Shen B-J, Takeuchi DT (2001) A structural model of acculturation and mental health status among Chinese Americans. Am J Comm Psych 29(3):387-418
6. Burnam MA, Hough RL, Karno M, Escobar JI, Telles C (1987) Sixmonth prevalence of specific psychiatric disorders among Mexican Americans and non-Hispanic whites in Los Angeles. Arch Gen Psychiatry 44(8):687-694

7. Vega WA, Kolody B, Aguilar-Gaxiola S, Alderete E, Catalano R (1998) Lifetime prevalence of DSM-III-R psychiatric disorders among rural and urban Mexican Americans in California. Arch Gen Psychiatry 55:771-782

8. Escobar JI, Hoyos Nervi C, Gara MA (2000) Immigration and mental health: Mexican Americans in the United States. Harv Rev Psychiatry 8(2):64-72

9. Medina-Mora ME, Conver TR, Sepulveda J, Otero MR (1989) Extenso del consumo de drogas en Mexico, Encuesta Nationales de Adicciones: resultados nacionales. Salud Mental 12(2):7-12

10. Escobar JI (1998) Immigration and Mental Health: Why are immigrants better off? Arch Gen Psychiatry 55:781-782

11. Escobar JI, Waitzkin H, Silver RC, Gara M, Holman A (1998) Abridged somatization: A study in primary care. Psychosom Med 60:466-472

12. Nazroo (1997) The health of Britain's ethnic minorities. Policy Studies Institute, London

13. Shaw CM, Creed F, Tomenson R, Riste L, Cruickshank JK (1999) Prevalence of anxiety and depressive illness and help seeking behaviour in African Caribbeans and white Europeans: two phase general population survey. BMJ 318:302-306

14. Robins LN, Regier DA (1991) Psychiatric disorders in America. New York: Free Press, New York

15. Kessler RC, McGonagle KA, Zhao S, et al. (1994) Lifetime and 12month prevalence of DSM-III-R psychiatric disorders in the United States. Arch Gen Psychiatry 51:8-19

16. Kessler RC, Berglund P, Demler O, et al. (2003) The Epidemiology of Depressive Disorder: Results from the National Comorbidity Survey Replication (NCS-R). JAMA 289(23):3095-3105

17. Miranda J, Chung JY, Green BL, Krupnick J, Siddique J, Revicki DA, Belin T (2003) Treating Depression in Predominantly LowIncome Young Minority Women: A Randomized Controlled Trial. JAMA 290(1):57-65

18. Dye J (2002) Fertility and Program Participation in the United States: 1996. US Census Bureau: Current Population Reports

19. Smith JC, Franchino B, Henneberry JF (1995) Surveillance of Family Planning Services at Title X Clinics and characteristics of women receiving these services, 1991. CDC Surveillance Summaries, May 5. MMWR; 44(no. 22-2):1-21

20. Spitzer RL, Williams JB, Kroenke K, et al. (1994) Utility of a new procedure for diagnosing mental disorders in primary care: the PRIME-MD 1000 study. JAMA 272:1749-1756

21. American Psychiatric Association, Committee on Nomenclature and Statistics (1994) Diagnostic and statistical manual of mental disorders. Rev $4^{\text {th }}$ ed. American Psychiatric Association, Washington, DC

22. Spitzer RL, Williams JBW, Kroenke K, Hornyak R, McMurray J (2000) Validity and utility of the PRIME-MD Patient Health Questionnaire in assessment of 3000 obstetric-gynecologic patients: The PRIME-MD Patient Health Questionnaire ObstetricsGynecology Study. Am J Obstet Gynecol 183:759-769

23. Russell M, Bigler L (1979) Screening for alcohol-related problems in an outpatient obstetric-gynecologic clinic. Am J Obstet Gynecol 134:4-12

24. Cherpital CJ, Clark WB (1995) Ethnic differences in performance of screening instruments for identifying harmful drinking and alcohol dependence in the emergency room. Alcohol Clin Exp Res 19(3):628-634

25. First MB, Spitzer RL, Gibbon M, Williams JBW (2001) Structured Clinical Interview for DSM-IV-TR Axis I disorders, Research Version, Non-patient Edition (SCID-I/NP). Biometrics Research, New York State Psychiatric Institute, New York, NY 